\title{
Scenario of Municipal Waste Management in Malaysia
}

\author{
Zachary Raphael Liew $^{1^{*}}$, Minhaj Uddin Monir ${ }^{2}$, Risky Ayu Kristanti ${ }^{3}$ \\ ${ }^{1}$ Department of Civil Construction Engineering, Faculty of Engineering Science, Curtin University, CDT 250, Miri, 98009 , \\ Sarawak, Malaysia \\ ${ }^{2}$ Department of Petroleum and Mining Engineering, Jashore University of Science and Technology, Jashore-7408, Bangladesh \\ ${ }^{3}$ Research Center for Oceanography, National Research and Innovation Agency, Jakarta, 14430, Indonesia \\ *Correspondence: zacharyraphaelliew@gmail.com
}

SUBMITTED: 26 November 2021; REVISED: 18 December 2021; ACCEPTED: 20 December 2021

\begin{abstract}
Malaysia has rapidly modernized, with most of the population now residing in cities and the remainder in rural or remote areas. The amount of municipal solid waste generated has increased in tandem with the country's rapid urbanization in response to that statement. Due to a lack of connectivity in rural areas, there may be insufficient infrastructure for a proper waste management system. As a result, illegal waste dumping was common, and landfills' massive volumes of waste may contribute to greenhouse gas emissions. The Malaysian government has responded by taking the necessary steps to upgrade the country's current waste management system in order to better manage municipal solid waste disposal. This research looks at how energy recovery from accumulated waste can be used as a renewable energy source, as well as the current issues, challenges, and proposed solutions. Methane gas produced as a byproduct of waste decomposition in landfills or disposal sites was used to generate electricity more efficiently and sustainably, resulting in a positive economic and environmental outcome.
\end{abstract}

KEYWORDS: Environment; landfill; incineration; pollution

\section{Introduction}

The amount of municipal solid waste generated in Malaysia has increased significantly as a result of rapid urbanization, particularly in densely populated areas. The government has spent a significant amount of money on waste collection, which is handled by local governments and private businesses. In the country, there are currently 170 waste disposal sites, 14 of which are designated as sanitary landfills [1]. Furthermore, some waste disposal sites are unable to meet demand due to rising waste volumes because they are nearing capacity or lack the necessary infrastructure. Furthermore, the amount of greenhouse gases emitted as a result of decomposition has steadily increased as a result of improper or uncontrolled solid waste management, causing environmental harm [2]. The development of Waste to Energy Systems (WTE) and Refuse Derived Fuel is proposed as a cost-effective and efficient waste management strategy for a more sustainable waste management system (RDF). This ensures that discarded waste is burned and converted into renewable energy and biofuel. As a result of the adoption of these innovative solutions, the amount of waste in landfills can be reduced by 
repurposing it into an environmentally friendly outcome. In Malaysia, several pilot plants for both WTE and RDF have been established, demonstrating that this initiative is feasible and could be scaled up significantly [3].

\section{Overview of major challenges}

Malaysia's municipal solid waste generation has gradually increased. To deal with the massive amount of waste, several cost-effective and environmentally friendly methods have been proposed, including Waste to Energy and Refuse Derived Fuel. These technologies make use of solid waste to generate renewable and sustainable energy as well as a biofuel alternative [4]. However, there are some difficulties in adapting to these practices. To begin with, there is the challenge of incorporating modern technologies. Due to technological advancements, other developing countries now have the necessary skills and knowledge to implement it [5]. In contrast to Malaysia, where our technology is considered to be below par or lagging behind that of other European or American countries, As a result, without proper guidance or support, it may be difficult to integrate it into the existing waste management system. Then there are environmental issues to consider, as well as public concerns. Even if WTE or RDF technologies have been successfully integrated into the waste management system, its complexity of nature, such as treatment or facilities, may still pose a problem. This is primarily due to the government's Environmental Quality (Dioxin and Furan) Regulation 2004 and a regulation from the United States Environmental Protection Agency imposing strict environmental standards. For example, Method 23 of the USEPA, for example, imposes strict emission requirements [6]. Should the control measures fail, it may be difficult to control and monitor the process, resulting in system compromise and increased carbon emissions and contamination. Following that, the required education and skills would be the next hurdles to overcome. There is a dearth of purposefully designated courses offered by higher learning institutions in Malaysia that educate students on solid waste planning, design, and management, as well as general facility and service maintenance [7]. Furthermore, there is a lack of technical skills and knowledge to have a fundamental understanding of waste management operations and how to integrate technologies such as WTE into the system because it is not properly taught to practitioners. Finally, government policies are a source of difficulty. The Malaysian government should play a key role in promoting the adoption of greener technology in the country's municipal waste management system, as well as exploring other options for developing a sustainable and renewable energy source to support the country's growth and development [8]. Furthermore, new policies could aid technological advancement while reducing reliance on nonrenewable energy sources such as fossil fuels.

\section{Review of approaches and studies}

Several approaches have been proposed to overcome the challenges mentioned above, such as the advancement of waste-to-energy and refuse-derived fuel technologies. Given the current state of Malaysia's resources and capabilities, collecting, transporting, and disposing of municipal solid waste could be difficult [9]. However, in other developing countries, such as Malaysia, waste by-products can be converted into gas, biofuels, and electricity thanks to the development of greener and more advanced technologies as shown in Figure 1. Because the amount of methane gas produced has steadily increased, releasing it directly into the atmosphere could be harmful to air quality [10]. It can, however, be used to generate heat or 
electricity by capturing the gases. Aside from that, the waste can be turned into biofuel. The majority of discarded solid waste is made up of food waste. Anaerobic digestion can refine the decomposition of food or other agricultural products into biomass, biogas, and biofuel [11]. These could be introduced as a replacement for Malaysia's current reliance on fossil fuels. In short, biogas production is beneficial because it reduces the amount of waste that ends up in landfills by converting it into cleaner and more sustainable by-products.

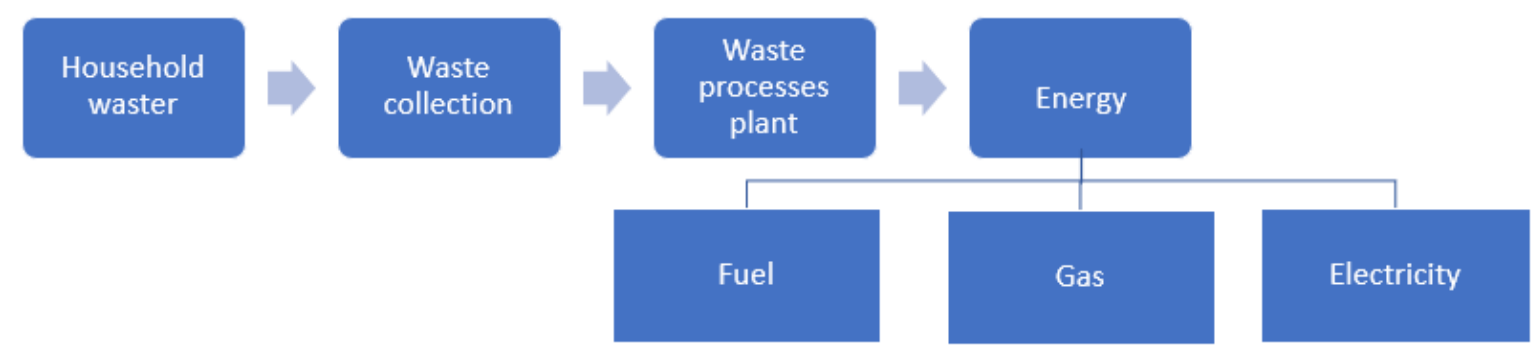

Figure 1. Profile of waste to energy in Malaysia

The introduction of policies is the next step in resolving the challenges of social and political issues in energy recovery. These measures protect both the government's and the public's interests while persuading them of the potential benefits of solid waste energy recovery [12]. Furthermore, strict environmental standards will be imposed to ensure that the solid waste management and treatment process is constantly regulated and monitored, protecting the public's health and safety [13]. Moving on, adapting current and future waste management facilities to accommodate modern technologies and equipment is another solution to the challenges of energy recovery applications. This gives disposal sites more flexibility in providing waste management services while also increasing renewable energy production [14]. For example, the current state of landfills and dump sites relies solely on waste disposal without any treatment. It will be possible to integrate various solid waste management systems by upgrading or building a purpose-built facility. Several methods for improving the overall operation are introduced, including waste gasification and incineration, to produce by-products that can be used. The integration will allow for a seamless transition from waste collection to disposal and treatment.

\section{Problems, issues, methods and result of approaches}

The challenges addressed by approaches to resolving issues based on the methods and results of energy recovery applications from municipal solid waste in Malaysia can first be thought of in terms of technological innovations. By incorporating advanced technologies into the wasteto-energy system, the quality and quantity of waste used to convert into by-products can be monitored [15]. The system will be able to control and monitor the entire process, from waste disposal to waste treatment, to ensure that at the end of the process, the performance is optimal. For example, a certain amount of solid waste must be converted into a form of energy to generate electricity. This output, however, may be influenced by the quality and consistency of the waste supply. It's worth noting that non-organic waste with a lower moisture content is suitable for thermal incineration, whereas organic waste with a higher moisture content is not. Then there's the issue of the environment. Several procedures, such as waste residual and 
emission management, must be followed in order to minimize further disruption to the surrounding environment [17]. The incineration process effectively reduces the amount of municipal solid waste that must be disposed of in landfills.

Residues such as fly ash accumulate at the end of the process and must be properly disposed of. Furthermore, in order to maintain air quality, strict emission standards must be met by treating air before it is released [18]. The facilities should be located away from populated areas, or a buffer zone can be built to further reduce the impact on the local environment. The economic and financial viability of energy recovery are next on the agenda. Waste treatment technologies (WTE) will be integrated into the waste management system to reduce waste disposal at landfills. To complete such a task, public and private investment are required to fund this initiative [19]. In terms of energy generation as well as capital and operational costs, the various WTE processes produce different results. The costs were also incurred as a result of daily operations and maintenance, contingencies, and resource allocation [20]. The government could also provide financial assistance or tax exemptions to waste management companies that have the potential to profit from the WTE process by selling electricity tariffs and carbon credits. The revenue generated generates economic benefits that can be used to fund future WTE project expansion across the country.

\section{Summary of field status and description of challenges}

Before it is implemented on a much larger scale, more research and development should be done to determine the feasibility of energy recovery applications from municipal solid waste [21]. The current state of waste generation by Malaysian states, as well as the estimated annual amount. Based on the data, it is expected to continue to rise unless drastic measures are taken to reduce the amount of waste generated. Landfills are the most common, affordable, and easily accessible method of waste disposal in the country. However, it is currently in high demand, making it difficult to keep up with the rapidly increasing volume of waste, resulting in most landfills reaching capacity [22]. As a result, other waste management methods, such as the introduction of WTE, are being investigated in order to effectively reduce the amount of waste. Anaerobic composting, anaerobic digestion, incineration, gasification, and pyrolysis are examples of biological and thermal processes used to convert waste into by-products [23]. Furthermore, landfill gas and biogas released by solid waste are captured and treated to produce renewable energy such as electricity and heat, which is then fed into the national grid.

Furthermore, with local and foreign investments as well as government funding, a purpose-built WTE plant can be built [24]. Other technologies, such as Refuse Derived Fuel, can be integrated into the facilities in addition to WTE (RDF). RDF is made up of combustible and non-combustible components that are separated, shredded, and burned as fuels to generate electricity as an alternative to fossil fuels. In terms of waste management strategies, Malaysia currently has only one fully operational plant in Kajang that converts solid waste into fuel, with plans to build a second one in Malacca. There will be a total of six proposed plants under the Ministry of Local Government and Housing's WTE projects, with the goal of reducing the country's reliance on fossil fuel while also reducing waste at landfills. A previous study evaluated those appropriate technologies as well as the technical capabilities for effectively treating solid waste. Energy recovery technologies are still being researched and developed for use in waste management. Despite initial challenges such as high operating costs and the cost 
of converting existing infrastructure to WTE facilities, there is an increasing demand for renewable and sustainable energy [25].

\section{Conclusion}

In a nutshell, Malaysia is a country endowed with an abundance of natural resources such as petroleum and natural gas. Both are non-renewable resources. There is, however, an alternative in the form of clean and sustainable energy derived from the treatment of municipal solid waste. The amount of waste discarded has increased significantly in recent years due to rapid population growth, contributing to landfill overcrowding. Apart from that, it has a negative effect on the environment as a result of carbon dioxide emissions caused by improper waste disposal and management. As the country advances, modern technologies, solutions, and innovations are being incorporated to mitigate and manage these issues. For instance, by promoting the development of waste-to-energy plants that effectively address both environmental and energy demand concerns. It has the potential to significantly reduce waste accumulated in landfills while also converting it into a renewable energy source for the national grid. Although landfills are the most cost-effective waste management option, I believe that WTE technologies are the best option in terms of practicality and long-term sustainability and should be widely adopted nationwide. Additionally, by implementing this strategy, Malaysia is able to achieve a sustainable development that benefits both the economy and the environment. Regardless of these efforts, communities can make a significant contribution to waste reduction by repurposing waste.

\section{Acknowledgments}

The authors thank Curtin University Malaysia for facilitating this work. Collaboration from University of Science and Technology Bangladesh, and Research Center for Oceanography, National Research and Innovation Agency, Indonesia are highly appreciated.

\section{Competing Interest}

The authors declare that they have no known competing financial interests or personal relationships that could have appeared to influence the work reported in this paper.

\section{References}

[1] Khamis, S.; Purwanto, H.; Rozhan, A.; Rahman, M.; Salleh, H. (2019). Characterization of Municipal Solid Waste in Malaysia for Energy Recovery. IOP Conference Series: Earth and Environmental Science, 264, 1-7. https://iopscience.iop.org/article/10.1088/17551315/264/1/012003.

[2] Noor, Z.; Yusuf, R.; Abba, A.; Hassan, M.; Din, M. (2013). An overview for energy recovery from municipal solid wastes (MSW) in Malaysia scenario. Renewable and Sustainable Energy Reviews, 20, 378-384. https://doi.org/10.1016/j.rser.2012.11.050.

[3] Kadir, S.; Yin, C.; Sulaiman, M.; Chen, X.; Harbawi, M. (2013). Incineration of municipal solid waste in Malaysia: Salient issues, policies and waste to energy initiatives. Renewable and Sustainable Energy Reviews, 24, 181-186. https://doi.org/10.1016/j.rser.2013.03.041.

[4] Aja, O.; Al-Kayiem, H. (2013). Review of municipal solid waste management options in Malaysia, with an emphasis on sustainable waste-to-energy options. Journal of Material Cycles and Waste Management, 16, 693-710. https://link.springer.com/article/10.1007\%2Fs10163-013-0220-z. 
[5] Kumaran, P.; Hephzibah, D.; Sivasankari, R.; Saifuddin, N.; Shamsuddin, A. (2016). A review on industrial scale anaerobic digestion systems development in Malaysia: Opportunities and challenges. Renewable and Sustainable Energy Reviews, 56, 929-940. https://doi.org/10.1016/j.rser.2015.11.069.

[6] Bashir, M.; Ng, C.; Sethupathi, S.; Lim, J. (2019). Assessment of the Environmental, Technical and Economic Issues Associated with Energy Recovery from Municipal Solid Waste in Malaysia. IOP Conference Series: Earth and Environmental Science, 268, 1-7. https://iopscience.iop.org/article/10.1088/1755-1315/268/1/012044/meta.

[7] Samsuddin, M.; Don, M. (2013). Municipal Solid Waste Management in Malaysia: Current Practices, Challenges and Prospects. Jurnal Teknologi, 62, 1-7. https://doi.org/10.11113/jt.v62.1293.

[8] Bong, C.; Ho, W.; Hashim, H.; Lim, J.; Ho, C.; Tan, W.; Lee, C. (2017). Review on the renewable energy and solid waste management policies towards biogas development in Malaysia. Renewable and Sustainable Energy Reviews, 70(1), 988 - 998. https://doi.org/10.1016/j.rser.2016.12.004.

[9] Moya, D.; Aldas, C.; Lopez, G.; Kaparaju, P. (2017). Municipal solid waste as a valuable renewable energy resource: a worldwide opportunity of energy recovery by using Waste-ToEnergy Technologies. Energy Procedia, 134, 286-295. https://doi.org/10.1016/j.egypro.2017.09.618.

[10] Thermelis, N.; Ulloa, P. (2007). Methane generation in landfills. Renewable Energy, 32, 12431257. https://doi.org/10.1016/j.renene.2006.04.020.

[11] Karmee, S.; Lin, C. (2014). Valorisation of food waste into biofuel: Current trends and technologies challenges. Sustainable Chemical Processes, 2, 22. http://dx.doi.org/10.1186/s40508-014-0022-1.

[12] Fazeli, A.; Bakhtvar, F.; Jahanshaloo, L.; Sidik, N.; Bayat, A. (2016). Malaysia's stand on municipal solid waste conversion to energy: A review. Renewable and Sustainable Energy Reviews, 58, 1007-1016. https://doi.org/10.1016/j.rser.2015.12.270.

[13] Arafat, H.; Jijakli, K.; Ahsan, A. (2015). Environmental performance and energy recovery potential of five processes for municipal solid waste treatment. Journal of Cleaner Production, 105, 233-240. https://doi.org/10.1016/j.jclepro.2013.11.071.

[14] Tan, S.; Hashim, H.; Lim, J.; Ho, W.; Lee, C.; Yan, J. (2014). Energy and emissions benefits of renewable energy derived from municipal solid waste: Analysis of a low carbon scenario in Malaysia. Applied Energy, 136, 797-804. https://doi.org/10.1016/j.apenergy.2014.06.003.

[15] Lombardi, L.; Carnevale, E.; Corti, A. (2015). A review of technologies and performances of thermal treatment systems for energy recovery from waste. Waste Management, 37, 26-44. https://doi.org/10.1016/j.wasman.2014.11.010.

[16] Lansing, S.; Viquez, J.; Martinez, H.; Botero, R.; Martin J. (2008). Quantifying electricity generation and waste transformations in a low-cost, plug-flow anaerobic digestion system. Ecological Engineering, 34, 332-348. https://doi.org/10.1016/j.ecoleng.2008.09.002.

[17] Milutinovic, B.; Stefanovic, G.; Dekic, P.; Mijailovic, I.; Tomic, M. (2017). Environmental assessment of waste management scenarios with energy recovery using life cycle assessment and multi-criteria analysis. Energy, 137, 917 - 926. https://doi.org/10.1016/j.energy.2017.02.167.

[18] Sciubba, E. (2003). Extended energy accounting applied to energy recovery from waste: The concept of total recycling. Energy, 28, 1315-1334. https://doi.org/10.1016/S0360-5442(03)00111$\underline{7}$

[19] Menikpura, S.; Sang-Arun, J.; Bengtsson, M. (2016). Assessment of environmental and economic performance of Waste-To-Energy facilities in Thai cities. Renewable Energy, 86, 576 - 584. https://doi.org/10.1016/j.renene.2015.08.054. 
[20] Tan, S.; Hashim, H.; Lee, C.; Taib, M.; Yan, J. (2014). Economical and Environmental Impact of Waste-To-Energy (WTE) Alternatives for Waste Incineration, Landfill and Anaerobic Digestion. Energy Procedia, 61, 704 - 708. https://doi.org/10.1016/j.egypro.2014.11.947.

[21] Consonni, S.; Giugliano, M.; Grosso, M. (2005). Alternative strategies for energy recovery from municipal solid waste: Part A: Mass and energy balances. Waste Management, 25, 123-135. https://doi.org/10.1016/j.wasman.2004.09.007.

[22] Ismail, S.; Manaf, L. (2013). The challenge of future landfill: A case study of Malaysia. Journal of Toxicology and Environmental Health Sciences, 5, 86-96. https://doi.org/10.5897/ JTEHS12.058.

[23] Tan, S.; Ho, W.; Hashim, H.; Lee, C.; Taib, M.; Ho, C. (2015). Energy, economic and environmental (3E) analysis of waste-to-energy (WTE) strategies for municipal solid waste (MSW) management in Malaysia. Energy Conversion and Management, 102, 111-120. https://doi.org/10.1016/j.enconman.2015.02.010.

[24] Tan, S.; Lee, C.; Hashim, H.; Ho, W.; Lim, J. (2014). Optimal process network for municipal solid waste management in Iskandar Malaysia. Journal of Cleaner Production, 71, 48-58. https://doi.org/10.1016/j.jclepro.2013.12.005.

[25] Cucchiella, F.; D’Adamo, I.; Gastaldi, M. (2017). Sustainable waste management: Waste to energy plant as an alternative to landfill. Energy Conversion and Management, 131, 18-31. https://doi.org/10.1016/j.enconman.2016.11.012.

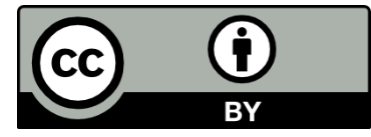

(C) 2021 by the authors. This article is an open access article distributed under the terms and conditions of the Creative Commons Attribution (CC BY) license (http://creativecommons.org/licenses/by/4.0/). 